\title{
Alignment Between Technology Acceptance And Instructional Design via Self-Efficacy
}

Robert J. Mills, Utah State University, USA

Matthew Harris, Dixie State University, USA

\begin{abstract}
As organizations continue to implement new technology solutions, the need for both technology training and examining technology acceptance of new implementations are necessary to determine the success or failure of a project. Unfortunately, instructional design considerations generally do not address technology acceptance, and leading technology acceptance models only classify training as an external variable or facilitating condition, with limited consideration in prior research. In this paper, we examine potential integration points between instructional design theory and technology acceptance. Specifically, we examine prior research on self-efficacy, Kirkpatrick's Model for Evaluating Training, Merrill's Component Display Theory, and Merrill's First Principles of Instruction.
\end{abstract}

Keywords: Technology Acceptance; Technology Training; Instructional Design; Technology Acceptance Model; Evaluation; Self-Efficacy

\section{INTRODUCTION}

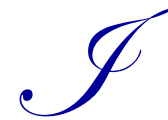

ncreases in technology solutions have dramatically changed the course of business and altered the tools necessary to survive in these highly competitive environments. Unfortunately, "organizations cannot realize any return on their investments in information systems (IS) unless the systems are actually used for their intended users" (Yi \& Hwang 2003, p. 431). Managing change associated with technological investments and implementations are no longer optional. While training for any new system is generally considered vital to the success of its adoption, training is, unfortunately, commonly seen "as separate and distinct from anything that brings bottom-line value to the organization," and one of the first budget items that gets cut (Rodgers 2008, p. 8). Although IS literature does address the importance of training to learn new technologies, few studies connect potential training design opportunities and the Technology Acceptance Model (TAM) (Marshall, Mills \& Olsen, 2008; Teo, 2009; Harris, Mills, Fawson \& Johnson, 2018).

In some ways, it's like two members of the same team not recognizing the shared goal to improve both learning and the acceptance of the new technology. While instructional designers focus on the process of designing and developing technology training, IS management focuses on technology acceptance and implementation. Missing at the intersection of instructional design and technology acceptance is an examination on where the two areas potentially intersect. Without additional examination, missed opportunities arise as a proper integration of design and technology acceptance is absent.

The purpose of this paper is to provide a theoretical introduction and discussion of prior research on technology acceptance, instructional design, evaluation, and self-efficacy to identify potential synergies between instructional designers and IS management at the nexus of instructional design and technology acceptance.

\section{A Technology Acceptance Perspective}

TAM uses the Theory of Reasoned Action (TRA) as a theoretical basis that focuses on two main constructs: perceived usefulness and perceived ease of use (Davis, Bagozzi \& Warshaw, 1989; Venkatesh, Morris \& Davis, 2003). In addition, users' attitudes, intentions, and actual computer adoption behavior are also incorporated into the model (Davis et al. 1989). Finally, a variable labeled 'external variables' is intended to serve as a bridge between what is presented in the model and other constraints and interventions (i.e., training) impacting behavior (Davis et al. 1989). 
Figure 1 illustrates the relationship between external variables and perceived usefulness and perceived ease of use. Although behavioral intentions to adopt or use new technologies are not based on actual usage, research indicates a strong positive relationship between behavioral intentions and actual use (Yi \& Hwang, 2003).

Figure 1. External Variables within TAM Context (Davis et al. 1989)

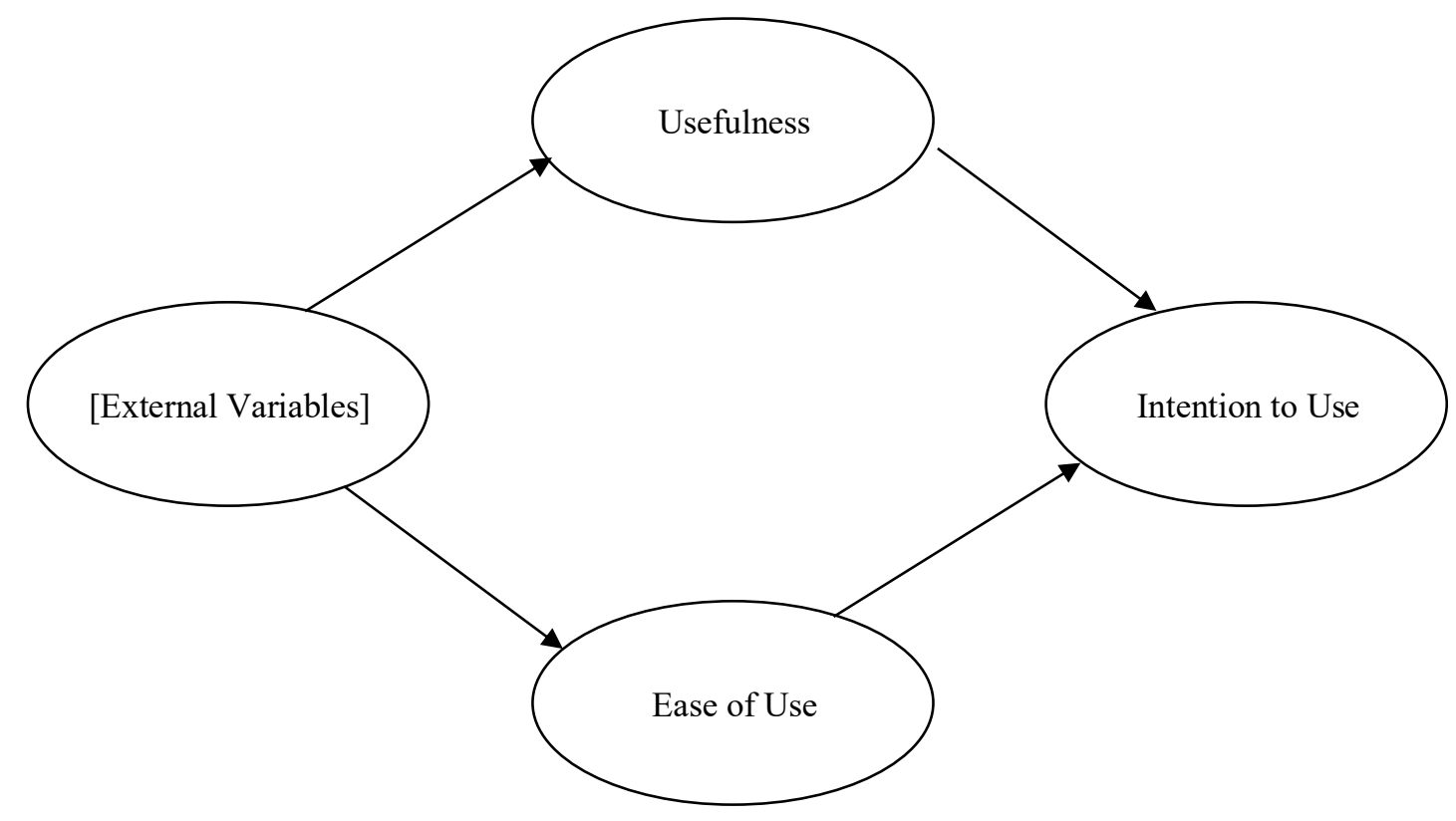

The Unified Theory of Technology Acceptance and Use (UTAUT) extends TAM but continues to largely ignore the impact of training on technology acceptance (Venkatesh et al. 2003). Prior research on UTAUT training impacts found training reactions and intentions to use technology partially mediated by facilitating conditions (similar to external variables in TAM) (Harris et al. 2018). Other research indicates end-user training improves performance expectancy and effort expectancy, both important variables when predicting technology acceptance (Marshall et al. 2008).

IT management are particularly interested in technology acceptance, which relies on models to explain the variance in technology acceptance and use (Marler, Liang \& Dulebohn, 2006). Prior research on technology acceptance and training involves learning how outcomes are affected by comparing various training delivery methods, differences in computer self-efficacy, individual differences, and the influence of perceived user resources (Gist, Schwoerer \& Rosen, 1989 Agarwal, 1999; Mathieson, Peacock \& Chin, 2001; Marler et al. 2006). Constructs including enjoyment and learning goal orientation have also been determined to have a positive impact on the actual use of new technologies (Yi \& Hwang 2003). Unfortunately, TAM lacks "guidance for managers on interventions that would be most effective in managing that technology acceptance." (Marler et al. 2006).

\section{An Instructional Design Perspective}

Examining instructional design considerations and strategies may provide insight regarding issues related to perceived usefulness and perceived ease of use, with a goal of improving overall technology acceptance. Deciding on a specific instructional design strategy is often based on the designer's academic background, understanding of theory (i.e., objectivism and constructivism), and specific instructional outcomes and objectives. This process is not an exact science, and dependent on the situation where one strategy is found to be more effective or efficient than another. When selecting a learning theory, the methodology and application of the instruction is considered in the decision process. 
For instruction that focuses on objective, content-centered instruction, Merrill's Component Display Theory (CDT) is well-researched and considered a seminal technique in instructional design theory literature (1983). CDT is built upon two main dimensions including performance along the vertical axis, and content along the horizontal axis (1983). Content, which includes the main body of knowledge to be learned, includes facts, concepts, procedures, and principles. Performance levels, which distinguish the level of knowledge being acquired, includes, remember, use, and find (Merrill, 1983). Instructional designers determine the appropriate learning content and performance level to help guide instructional strategy and specific learning outcomes.

Once the content and performance levels have been determined, Merrill provides primary and secondary presentation forms for developing training. Primary Presentation Forms (PPF) provide a prescriptive, and detailed approach to design that includes: rules, examples, recall, and practice (1983). The Secondary Presentation Forms (SPF) provide additional instructional strategies to improve the PPFs and include addressing prerequisites, including instructional objectives, providing adequate helps and guidance, introducing mnemonics when appropriate, and appropriate feedback. Research suggests that following all PPFs produces better performance outcomes than instruction missing one or more PPFs (Mills, 2001).

Merrill's First Principles of Instruction (FPI) (2002) is an instructional design theory which incorporates best practices from a variety of learning theories. A problem or specific real-world challenge represents the heart of FPI and drives the instructional strategy. To improve the instruction, additional considerations are addressed including activation of prior knowledge, demonstration, application (i.e., let the user practice different problems in increasing difficulty, and integration of the learning back to the workplace (Merrill, 2002). Both prerequisite knowledge and activation are supported by research that finds linking new information to prior knowledge improves learning and facilitates the transfer process (Catrambone \& Holyoak, 1989).

Although there are several models for evaluating training effectiveness, Kirkpatrick's Four-Level Model (Kirkpatrick, 1979) is widely considered the most commonly used model in corporate training assessment. This model consists of four levels including Level 1 - training reactions, Level 2 - learning outcomes, Level 3 - behavior or transfer, and Level 4 - results or return on investment. Prior research indicates about $92 \%$ of companies use training reactions and feedback as a primary method to evaluate training effectiveness and learning outcomes (Patel, 2010).

Prior research illustrates the importance of improving sell-efficacy through instruction design strategy (Clinton \& Hokanson, 2012). Self-efficacy helps or hinders a learner's "efforts to learn even when intelligence and basic learning skills are adequate to do the learning tasks at hand" (Yang \& Park, 2011-2013, p. 325). In a prior investigation to predict the use of a new web-based system by examining self-efficacy and TAM, self-efficacy was found to have a positive effect on ease of use (Yi \& Hwang 2003). Figure 2 introduces how the TAM was extended to include selfefficacy, and its relationship to 'ease of use' in the Yi and Hwang (2003) study.

Prior knowledge, mastery experiences (prior success), vicarious experience (success of others), verbal persuasion as feedback, usable and accessible environments (i.e., message design and usability), and self-regulation (i.e., cognitive strategies) have also been found to impact self-efficacy (Hodges, 2013). Additional considerations that positively impact self-efficacy include allowing learners to take risks and having them not be concerned with making mistakes (Hardre \& Kollmann, 2013). Finally, understanding learning requirements, success opportunities, and personal responsibility are also positive design factors related to improved student performance, confidence and improved selfefficacy (Keller, 1987; Mills \& Sorensen, 2004). 
Figure 2. Self-Efficacy and TAM (Davis et al. 1989; Yi \& Hwang, 2003)

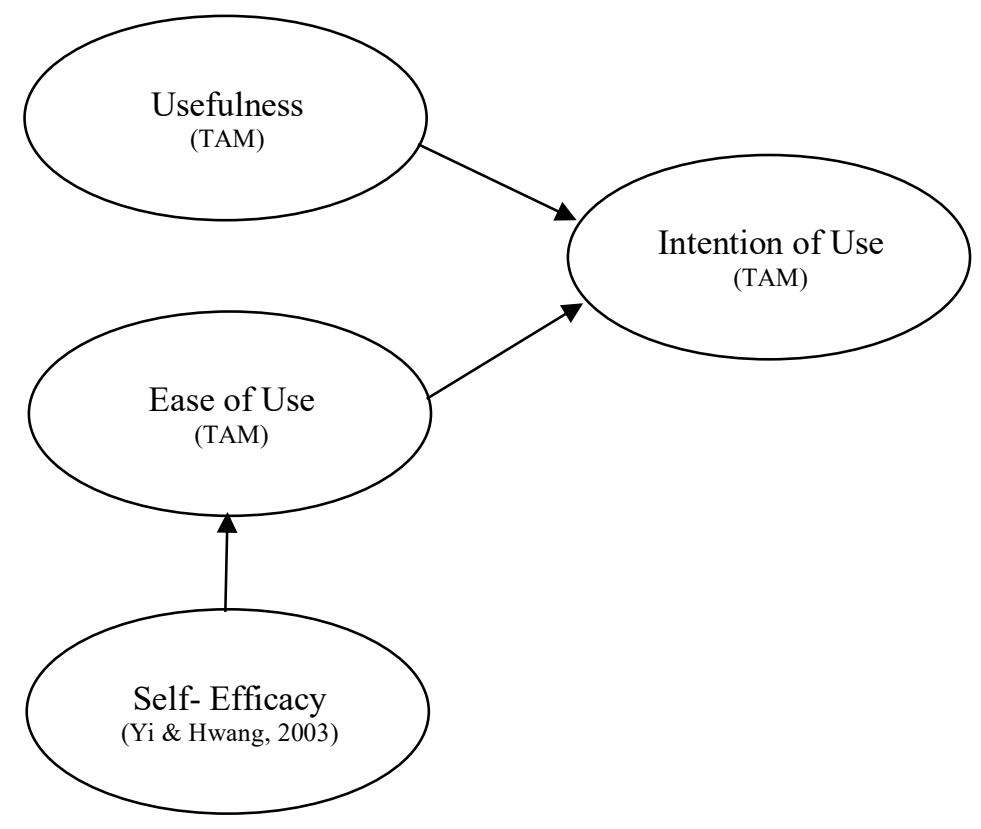

\section{Training and TAM Alignment Opportunities}

Considering the importance of TAM's analyses of both perceived usefulness and perceived ease of use, why don't instructional design theories incorporate these elements on all IT projects? Since instructional design is not exclusively used for technology training, models wouldn't likely include specifics for handling perceived usefulness and perceived ease of use. However, effective design strategies, in general, have the potential to positively impact technology transfer.

Prior research on self-efficacy, as it relates to both TAM and instructional design, provides a foundation for aligning the two areas to help improve, as opposed to only measuring, technology acceptance. Building upon Yi and Hwang (2003), Figure 3 includes the self-efficacy in the context of TAM, and further adds instructional design strategy. 
Figure 3. Instructional Design Impacting TAM and Self-Efficacy

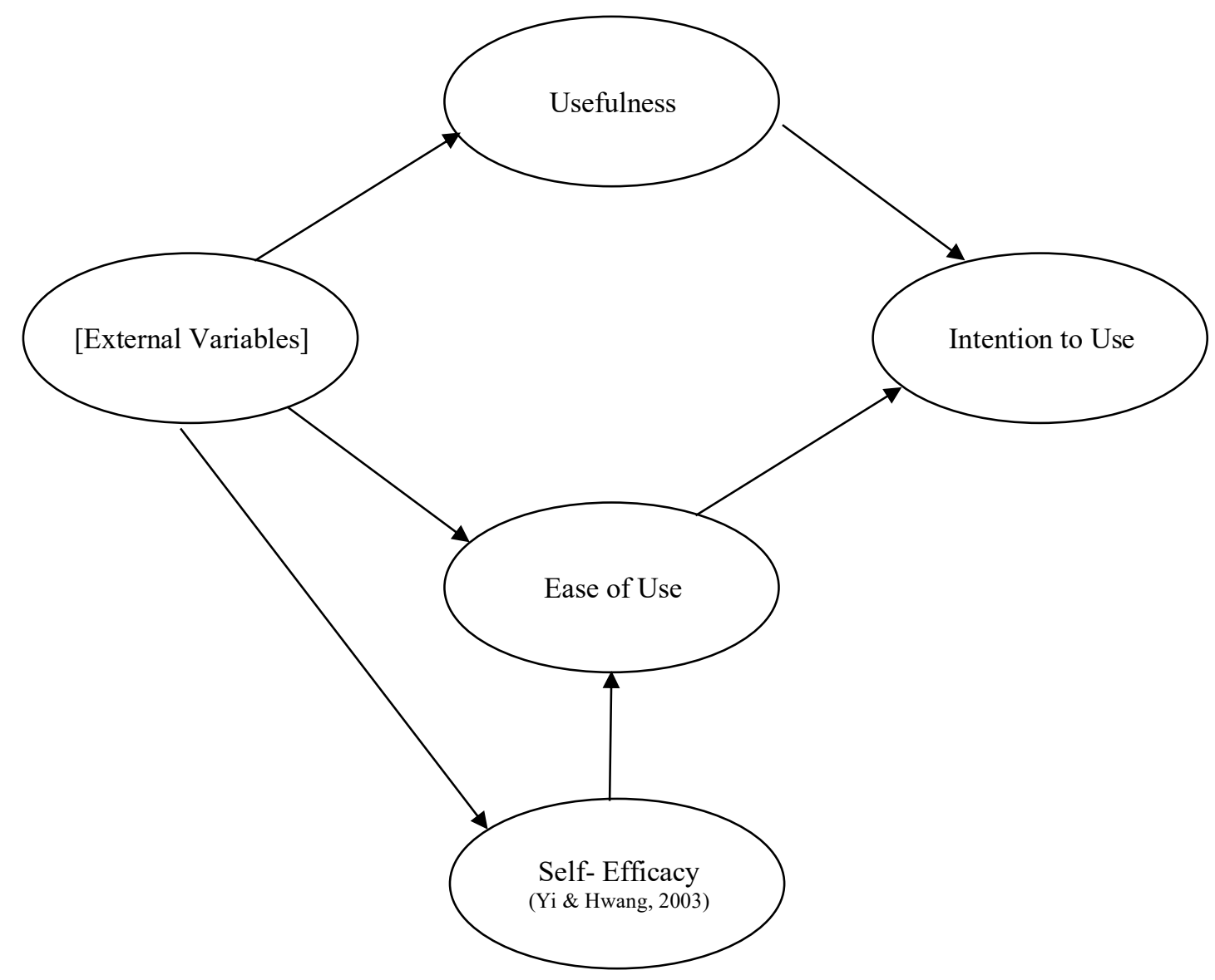

Based on the review of literature review, twelve specific instructional design strategies were identified to help improve self-efficacy (Figure 4). These strategies include: activation of prior memory, mastery experiences, vicarious experiences, verbal persuasion, message design, self-regulation, learning objectives, success opportunities, personal responsibility, risk taking, allowing mistakes, and scaffolding. 
Figure 4. Design Strategies Focused on Self-Efficacy and TAM

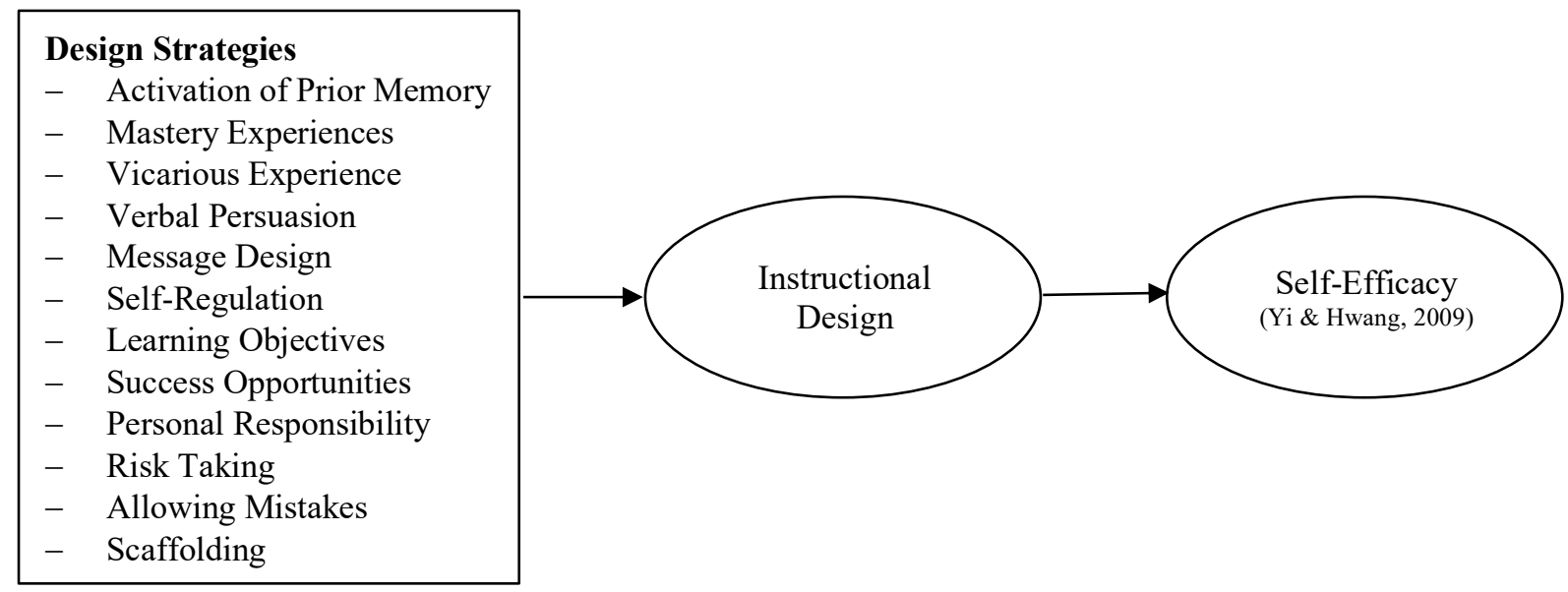

Merrill's CDT and FPI includes prerequisites and activation of memory. By strategically addressing a learner's prerequisite knowledge effectively, TAM perceived usefulness and perceived ease of use should increase (Figure 5). Without proper links to prerequisite knowledge, the knowledge gap increases, which also increases the likelihood that perceived ease of use and usefulness will decrease. Prior knowledge is also related to mastery experience, where learners can improve self-efficacy and build on prior successes (Hodges, 2013).

Figure 5. Potential TAM and FIP Prerequisites

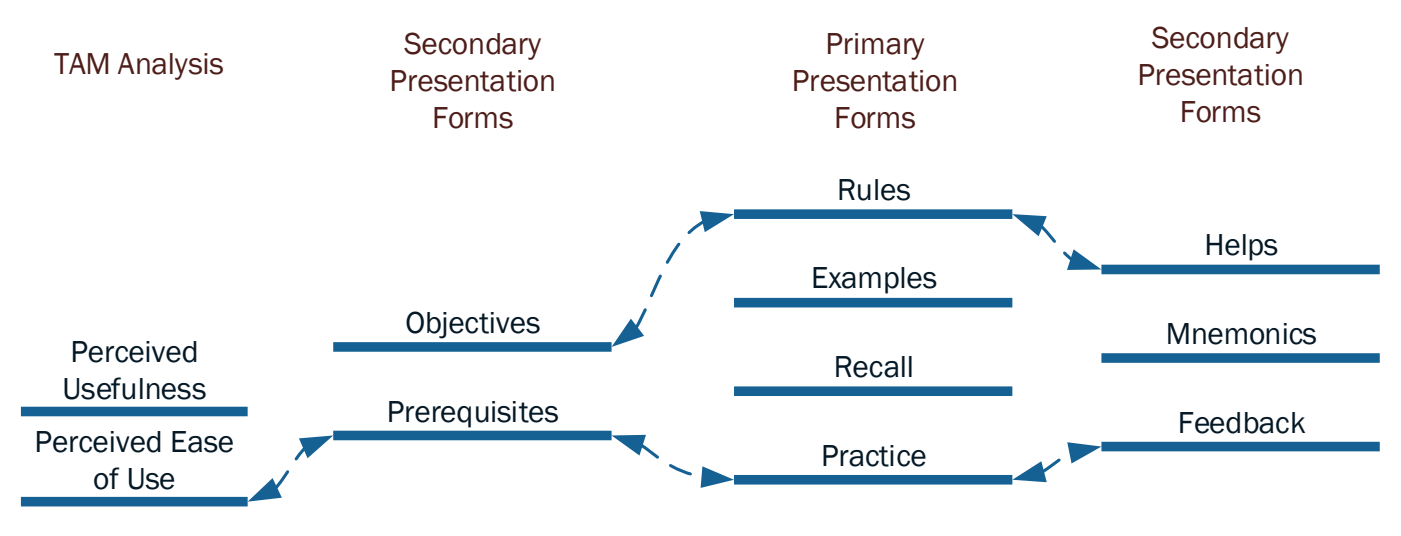

CDT and FPI also include opportunities for presentation, and encouraging the use of success experiences of others, which is called vicarious experiences (Merrill, 1983; Merrill, 2002; Hodges, 2013). When presenting worked examples, and a progression of problems, it's important to learn from other's experiences as a way to make the instructional presentation both efficient and effective (Atkinson, Derry, Renkle \& Wortham, 2000; Wong, Leahy, Marcus \& Sweller, 2012). In addition to improving self-efficacy, vicarious experiences have also been demonstrated to reduce cognitive load (Wong et al. 2012; Kalyuga \& Singh, 2016).

Also included on the list of 12 and based on prior research related to Kirkpatrick's ARCS Motivational Model, the importance of establishing clear learning objectives, success opportunities, and personal responsibility included as specific design strategies that potentially impact self-efficacy (Keller, 1987). Dynamic content leveling is an example of a motivational instructional strategy used to ensure success opportunities as it allows individualized instruction allowing learners to progress at individual levels (Mills \& Sorensen, 2004). 
Finally, message design, verbal persuasion, self-regulation, risk taking, allowing mistakes, and scaffolding complete the list of 12 (Yi \& Hwang, 2003; Marler et al. 2006; Yang \& Park, 2011-2013). Together, this list of 12 strategies represent a basis for instructional design considerations to better facilitate technology implementation via self-efficacy improvements.

\section{CONCLUSION}

This paper provides a conceptual introduction identifying potential synergies between instructional designers and IS management to incorporate TAM analysis into training design. Self-efficacy, given its importance to both TAM and instructional design provide a foundation link between the two areas, especially when focused on perceived ease of use. Although there are number of design strategies related to improving self-efficacy, we identified 12 from prior research that appear promising with regards to technology acceptance. Given the importance of ensuring new technologies are accepted, it's not enough to only use TAM to predict a successful or unsuccessful implementation. Designers and IT management can proactively work together to help improve technology acceptance within an organization.

Regarding Merrill's CDT and FPI, future research and consideration of TAM elements could be incorporated in a variety of areas. Specifically, activation of memory (CDT), and prerequisite knowledge (FPI) were identified conceptually as a logical area for designers and IT managers to focus. This effort helps bridge new knowledge with prior Merrill's FPI includes elements of activation, which involves understanding a learner's prior knowledge to help add new content, and integration, which allows the learner to apply what they have learned to a variety of situations Similar to CDT, careful consideration of essential prior knowledge would likely increase TAM considerations of perceived ease of use and perceived usefulness.

While Kirkpatrick's Evaluation Model doesn't specifically incorporate TAM elements, the model provides two logical links to TAM and warrants further investigation. First training reactions commonly ask questions related to perceived usefulness, and perceived ease of use. This intersection provides a logical area for designers and IT managers to formally incorporate TAM into the evaluation design, both at the formative level (Level 1 - Training Reactions), and summative level (Level 3 - Transfer of Training). Additional research on formally incorporating and empirically studying the integration of TAM and Kirkpatrick's Evaluation Model are recommended for improved technology implementation and evaluation.

Additional research is also recommended to examine how design strategies could be customized to address TAM's usefulness and perceived ease of use when creating technology training. How can considerations related to selfefficacy, prerequisite knowledge and activation of memory be incorporated into design to improve learning and transfer? For instance, advance organizers and analogous learning are both considered effective strategies to link new knowledge to existing structures (Ausubel, 1960; Togo 2002; Cellucci, Layman, Campbell \& Zeng, 2011). How could they be used to improve technology transfer.

Examining TAM and training theory integration is also warranted for other types of design theories. Merrill's CDT and FPI are considered largely objectivist approaches to learning and examining other theoretical design approaches, such as constructivism, may also provide insight on how to design training to improve acceptance levels of new information technology solutions. Future research will help determine if TAM external variables and UTAUT's facilitating conditions can be more effectively used to improve technology transfer, and perhaps instructional design strategy will be part of the solution.

\section{RESEARCH NOTE}

This research is based, in part, on the unpublished dissertation of Dr. Matthew Harris: "Incorporating a Training Construct into the Unified Theory of Acceptance and Use of Technology" (2016). All Graduate Theses and Dissertations. 4776. https://digitalcommons.usu.edu/etd/4776/ 


\section{AUTHOR BIOGRAPHY}

Robert J. Mills is a Professor of Management Information Systems in the Jon M. Huntsman School of Business at Utah State University. His research interests focus at the nexus of MIS education and instructional design. Specific interest includes educational trends in MIS, analogical learning, SQL instruction, MIS enrollments, cognitive load, and knowledge transfer. Bob has consulted for a variety of organizations including Silicon Graphics International (SGI), EnergySolutions Arena / Utah Jazz, International Center for Captive Insurance Education (ICCIE), and IBM on technology training initiatives. His research has been published in the Communications of the AIS, the Journal of Information Systems Education, The Journal of Literacy Research, and the Journal of Computer Information Systems. E-mail: bob.mills@usu.edu

Matthew E. Harris is an Assistant Professor of Management Information Systems in the Udvar-Hazy School of Business at Dixie State University. Matt's research interests include data analytics, technological innovation, augmented reality, computer-based learning environments, technology acceptance, the Internet of things, healthcare informatics, MIS education, and strategic technology application in business. He also serves as a small-business technology consultant for several for-profit and non-profit organizations.

\section{REFERENCES}

Agarwal, R. (1999). Are individual differences germane to the acceptance of new information technologies? Decision Sciences 30(2), 361-391.

Atkinson, R.K., Deery, S.J, Renkle, A. \& Wortham, D. (2000). Learning from examples: Instructional principles from the worked examples research. Review of Educational Research, 70(2), 181-216.

Ausubel, D.P. (1960). The use of advance organizers in the learning and retention of meaningful verbal material. Journal of Educational Psychology, 51, 267-272.

Catrambone, R. \& Holyoak, K.J. (1989). Overcoming contextual limitations on problem-solving transfer. Journal of Experimental Psychology: Learning, Memory, and Cognition, 15, 1147-1156.

Cellucci, L.W., Layman, E.J., Campbell, R. \& Zeng, X. (2011). Integrating healthcare ethical issues into is education. Journal of Information Systems Education, 22(3), 295-310.

Clinton, G. \& Hokanson, B. (2012). Creativity in the training and practice of instructional designers: the design/creativity loops model. Educational Technology Research and Development, 20, 111-130.

Davis, F.D., Bagozzi, R.P. \& Warshaw, P.R. (1989). User acceptance of computer technology: A comparison of two theoretical models. Management Science, 35(8), 982-1003.

Gist, M.E., Schwoerer, C., \& Rosen, B. (1989). Effects of alternative training methods on self-efficacy and performance in computer software. Journal of Applied Psychology, 74(6), 884.

Hardre, P.L. \& Kollmann, S. (2013). Dynamics of instructioal and perceptual factors in instructional design competence development. Journal of Learning Design, 6(1), 43-48.

Harris, M., Mills, R.J., Fawson, C. \& Johnson, J.J. (2018). Examining the impact of training in the unified theory of acceptance and use of technology. Journal of Computer Information System,s 58(3), 221-233.

Hodges, C.B. (2013). Suggestions for the Design of E-Learning Environments to Enhance Learner Self-Efficacy. IADIS International Conference on Cognition \& Exploratory Learning in Digital Age.

Kalyuga, S. \& Singh, A.M. (2016). Rethinking the boundaries of cognitive load theory in complex learning. Educational Psychology Review, 28, 831-852.

Keller, J.M. (1987). Strategies for stimulating the motivation to learn. Performance and Instructon, 26(8), 1-7.

Kirkpatrick, D.L. (1979). Techniques for evaluating training programs. Training \& Development Journal, 33(6), 78-92.

Marler, J.H., Liang, X. \& Dulebohn, J.H. (2006). Training and Effective Employee Information Technology Use. Journal of Management, 32(5), 721-743.

Marshall, B.A., Mills, R. J., \& Olsen, D. (2008). The role of end-user training in technology acceptance. Review of Business Information Systems 12(2), 1-8.

Mathieson, K., Peacock, E. \& Chin, W.W. (2001). Extending the Techology Acceptance Model: The influence of perceived user resources. ACM SIGMIS Database, 32(3), 86-112.

Merrill, M.D. (1983). Component display theory. Instructional Design Theories and Models. C. Reigeluth. Hillsdale, NJ, Erlbaum Associates.

Merrill, M.D. (2002). First principles of instruction. Educational Technology Research and Development, 50(3), 43-59.

Mills, R.J. (2001). Analyzing instructional software using a computer-tracking system. Information Technology Learning and Performance, 19(1), 21-30.

Mills, R.J. \& Sorensen, N. (2004). Kids CollegeTM 2004: An implementation of the arcs model of motivational design. from https://www.researchgate.net/publication/303786447_Kid\%27s_College_TM_2004_An_implementation_of_the_ARC 
S_model_of_motivational_design.

Patel, L. (2010). Overcoming barriers and valuing evaluation. $T+D, 64(2), 62-63$.

Rodgers, K. (2008). Ups and downs [Electronic Version]. Analysis: industry insight. from http://www.g2i.org/article/2008/08/ups-and-downs.

Teo, T. (2009). Evaluating the Intention to Use Technology Among Student Teachers: A structural equation modeling approach. International Journal of Technology in Teaching and Learning, 5(2), 106-118.

Togo, D.F. (2002). Topical sequencing of questions and advance organizers impacting on student's examination performance. Accounting, 11(3), 203-216.

Venkatesh, V., Morris, M. G., \& Davis, F. D. (2003). User acceptance of information technology: Toward a unified view. MIS Quarterly, 27(3), 424-478.

Wong, A., Leahy, W., Marcus, N. \& Sweller, J. (2012). Cognitive load theory, the transient information effect and e-learning. Learning and Instructoin, 22, 449-457.

Yang, Y. \& Park, E. (2011-2013). Applying strategies of self-regulation and self-efficacy to the design and evaluaton of online learning programs. Journal of Educational Technology Systems, 40(3): 323-335.

Yi, M.Y. \& Hwang, H. (2003). Predicting the use of web-based information systems: self-efficacy, enjoyment, learning goal orientation, and the technology acceptance model. International Journal of Human-Computer Studies, 59(4), 431-449. 
NOTES 